\title{
Babel: Cine y comunicación en un mundo globalizado
}

\author{
Carmen Pereira Domínguez* \\ Jordi Solé Blanch** \\ Luis Fernando Valero Iglesias ${ }^{* * *}$
}

\begin{abstract}
Resumen: En este artículo se presenta una propuesta formativa utilizando el cine como material cultural y fuente de conocimiento. Una película como Babel permite trabajar la globalización y la educación de la ciudadanía, con planteamientos que exigen un nuevo humanismo, una nueva relación interpersonal, conscientes de los problemas de comunicación, prejuicios y choques culturales derivados del desarrollo tecnológico. La película cuestiona esta existencia en un mundo global interrelacionado, evocando el viejo mito bíblico de la Torre de Babel haciendo énfasis en identificaciones erróneas, malentendidos y oportunidades fallidas, como manos invisibles que nos guían; o el fin cuyo destino se nos escapa. Babel hace comprender la realidad de la globalización. Nos permite observar cuatro lugares tan distantes como Estados Unidos, Méjico, Marruecos y Japón, no sólo distanciados físicamente. Los cuatro países representan estilos culturales diferentes, tres formas de realización humana. Asistimos al choque, a la incomunicación personal, al aislamiento por la diferencia de cultura y la ficticia proximidad tecnológica. Vivimos juntos, pero aislados los unos de los otros.
\end{abstract}

Palabras clave: Educación, cine, comunicación, globalización, multiculturalidad.

\section{Babel: Cinema and communication within a globalized world}

\begin{abstract}
In this article is presented a formative proposal using the cinema as a cultural material and as a source of knowledge. A film like Babel offers a good material in order to approach globalization and citizenship education, with propositions that demand a new humanism, a new relationship among people, aware of the communication problems, prejudices and cultural collisions derived from technological development. The film Babel questions the existence in a globalize world where everything is interrelated, for this purpose it brings the old biblical myth of the Tower of Babel emphasising wrong identifications, misunderstandings and failed opportunities, as invisible hands that guide our lives; or where destiny eludes us. Babel enables to understand globalize reality. It also allows us to be almost present in four different places as far as USA, México, Morocco and Japan, not only physically
\end{abstract}

\footnotetext{
* Universidad de Vigo. Campus Orense. Orense. España. E-mail: mcdguez@uvigo.es

** Universitat Oberta de Catalunya. Barcelona. España. E-mail: jsolebla@uoc.edu

*** Universidad Rovira i Virgili. Tarragona. España. E-mail: luis.valero@urv.cat
} 
distant. We see the contradiction of miscommunication and isolation due to cultural difference in spite of the fictitious technological proximity. We live together, but isolated from one another. diversity.

Key words: Education, cinema, communication, globalization, cultural

\section{Babel: filme e comunicação num mundo globalizado}

Resumo: O presente artigo apresenta uma proposta formativa utilizando o cinema como material cultural e fonte de conhecimento. Um filme como Babel permite trabalhar a globalização e a educação para a cidadania, com abordagens que exigem um novo humanismo, um novo relacionamento interpessoal, conscientes dos problemas de comunicação, preconceitos e choques culturais derivados do desenvolvimento tecnológico. $\mathrm{O}$ filme questiona a existência em um mundo global interconectado, evocando o velho mito bíblico da Torre de Babel, enfatizando identificações errôneas, mal-entendidos e oportunidades perdidas, como a mão invisível que nos guia; ou o destino que nos escapa. Babel permite compreender a realidade da globalização. Nos permite observar quatro lugares tão distantes como os Estados Unidos, México, Marrocos e Japão, não apenas distanciados fisicamente. Os quatro países representam estilos culturais diferentes, três formas de realização humana. Testemunhamos o choque, a impossibilidade de comunicação pessoal, o isolamento a partir da diferença de cultura e a fictícia proximidade tecnológica. Vivemos juntos, mas, isolados uns dos outros.

Palavras-chave: educação, cinema, comunicação, globalização, multiculturalismo.

Recibido: 09.11.2009

Aceptado: 30.06.2010

$* * *$

"Creo que los idiomas pueden ser como espejismos que nos engañan y confunden. Pueden hacer que desconfiemos de los otros. Y creo que no hay mejor herramienta para romper la barrera del idioma que la fuerza de

la imagen y de la música. No es necesario traducir una imagen porque despierta emociones universales. El cine es un auténtico esperanto”

Alejandro González Iñárritu

\section{Cine, entretenimiento y educación superior}

El cine no sólo ha sido el arte por antonomasia del siglo XX, sino fuente de entretenimiento y evasión compartida por parte de un público global de cualquier clase y condición. Por esta misma razón ha sido y sigue siendo una fuente de conocimiento. Una fuente de conocimiento que, a

${ }^{1}$ Frase del director de la película Babel recogida por Manuel Hernández Martínez (2008: 76), ver en bibliografía. 
diferencia de lo que a menudo se aprende en la enseñanza formal, es capaz de conectar el placer con el significado ${ }^{2}$.

Las películas hacen algo más que divertir. Giroux afirma en Cine y entretenimiento que las películas ofrecen posiciones al sujeto, movilizan nuestros deseos, nos influyen inconscientemente y nos ayudan a construir un fresco de nuestra cultura. En este sentido, el cine representa una metáfora viva de la realidad. "Profundamente ligadas a las relaciones materiales y simbólicas del poder, las películas producen e incorporan ideologías que representan el resultado de luchas que marcaron las realidades históricas del poder y las angustias de los tiempos, también son un despliegue del poder en el sentido que desempeñan un papel que conecta la producción del placer y el significado de los mecanismos y la práctica de máquinas poderosamente pedagógicas. Dicho simple y brevemente, las películas entretienen y enseñan a la vez” (Giroux, 2003: 15).

Conscientes de ello, hace tiempo que empleamos el cine en nuestro trabajo docente como profesores del sistema de educación superior, a modo de experiencia interuniversitaria. Las imágenes en sentido genérico, y el cine en particular, posee formas discursivas que la cultura académica debe incorporar en la formación universitaria (Aparici y García Matilla, 2008). De alguna forma, y siguiendo de nuevo a Giroux (2003), debemos hacer un esfuerzo por comprender la naturaleza constitutiva y política del cine. Al ser una forma de pedagogía pública, las películas combinan entretenimiento y política y nos proporcionan instrumental teórico con el que ofrecer perspectivas alternativas a los estudiantes (Cuenca, 2005, Buitrago y Pereira, 2007). Por otro lado, el cine nos puede proporcionar atractivos textos culturales porque no está contaminado por la lógica de la enseñanza formal constituyendo, así, una fuente viable de conocimiento.

De acuerdo con los contenidos que desarrollamos en nuestras asignaturas (destinadas a educadores del ámbito formal y no formal) lo usamos como fuente analítica y documental para la reflexión socioeducativa. Los relatos fílmicos nos permiten incorporar prácticas formativas a partir del análisis de casos, una herramienta de trabajo muy utilizada en el campo de la Educación Social. Pero la introducción de la cultura cinematográfica entre los alumnos universitarios, que están llamados a formar a nuestras futuras generaciones, ofrece también la oportunidad de tomar un contacto implícito con contenidos que no esquivan la reflexión moral (Talens y Zunzunegui 1995, Josso 2000, Pereira 2005, Gutiérrez, Pereira y Valero

\footnotetext{
${ }^{2}$ Existen numerosas experiencias desde el mismo nacimiento del cine que señalan esta doble dimensión didáctica y ociosa. Las primeras filmaciones de finales del siglo XIX, por ejemplo, trataron de mostrar actos de la vida diaria: La sortie des Usines Lumiére a Lyon, 1895 (La salida de la fábrica Lumière en Lyon Monplaisir) y L'arroseur arrosé, 1895 (El regador regado) de los hermanos Lumière, el primer filme de humor, de un minuto, de la historia del cine, son una buena muestra de ello. En España encontramos la Salida de misa de doce de la Iglesia del Pilar de Zaragoza, en 1896, de Eduardo Jimeno.
} 
2006, Solé, Gómez y Gimeno 2007 y Escámez, García, Pérez y Llopis $2007)^{3}$.

El cine permite proyectar múltiples formas de representación de la realidad y de los tiempos que vivimos, donde se entrecruzan nuestros deseos y nuestros miedos. Es un dispositivo de espectáculo, pero también de comunicación, capaz de sensibilizarse con los problemas actuales. Si el cine es un referente cultural de primer orden, tal vez ya no el más importante si atendemos el lugar que ocupan los telefilmes y las teleseries, Internet y los videojuegos en la vida de los jóvenes y no tan jóvenes, es importante trabajar a partir del material que produce, porque éste pone de relieve el mundo social que nos envuelve y su diversidad cultural (Gubern 1988, Hueso 1998, Pérez Rubio 2004, Bergala 2008 y Caride, 2009).

Manuel Castells (2009) en Comunicación y poder nos indica que hay un cambio sustantivo en la sociedad actual en donde se conjugan los diversos elementos de esta nueva sociedad. Así, el cine, la televisión, la publicidad, el ocio, Internet, el libro digital, etc., establecen una sociedad concreta: "la sociedad red, la estructura social que caracteriza a la sociedad a principios del siglo XXI, una estructura social construida alrededor de (pero no determinada por) las redes digitales de la comunicación. Sostengo que el proceso de formación y ejercicio de las relaciones de poder se transforma radicalmente en el nuevo contexto organizativo y tecnológico derivado del auge de las redes digitales de comunicación global y se erige en el sistema de procesamiento de símbolos fundamental de nuestra época. Por tanto, para analizar las relaciones de poder es necesario comprender la especificidad de las formas de y procesos de la comunicación socializada, que en la sociedad red se refiere tanto a los medios de comunicación multimodales como a las redes de comunicación inalámbrica. Efectivamente, estas redes horizontales posibilitan la aparición de lo que llamo 'autocomunicación de masas', que incrementa de forma decisiva la autonomía de los sujetos comunicantes respecto a las empresas de comunicación en la medida en que los usuarios se convierten en emisores y receptores" (Castells, 2009:25).

De acuerdo con el momento y la cultura que nos ha tocado en suerte, donde no reluce el brillo de la responsabilidad, de la tolerancia y del es-

\footnotetext{
${ }^{3}$ Esta experiencia que hemos desarrollado entra en el ámbito de la especialización en la carrera de Educación Social que tiene, como señala Molina (2003) "la acción y la actividad educativas”. Para este segundo desarrollo recurrimos al tránsito que empieza con la diferencia (no contraposición) establecida por Aristóteles entre praxis y poiesis (retraducidas para la ocasión como acción y actividad), y que es retomada por pensadores contemporáneos de la talla intelectual de Karl Marx, Hanna Arendt o Cornelius Castoriadis.

Aunque el marco de acción en este caso han sido los estudiantes de Educación Social, creemos que la metodología y el análisis son aplicables a cada estamento del sistema escolar, en sus diferentes etapas, con las adecuaciones convenientes, conjugando los intereses del alumnado. Es obvio que el profesorado motivado en estas experiencias pedagógicas interuniversitarias sabrá distinguir esas variables y su aplicabilidad.
} 
fuerzo, debemos incidir en una decidida educación en valores si nuestro objetivo lo conforman unos futuros educadores sociales competentes y comprometidos con los tiempos que corren (Ferrés 2007 y Sáez 2009). Los valores marcan el camino de nuestra actividad, moldean la conducta y forjan la contundencia de las opiniones. Ya no es permisible dudar de su esencialidad formativa. Pedagógicamente, el cine cumple con las condiciones de agente educador, si somos capaces de inculcar el análisis y la crítica sobre los argumentos a tratar por parte del espectador (Martínez-Salanova 2002, González 2004, Prats 2005, Torre, Pujol y Rajadell 2005 y Hernández 2008).

Si el cine se vincula con el pensamiento filosófico, no debemos olvidar los lazos que mantiene con la sociedad y la cultura. Tal y como apuntan Lipovetsky y Serroy (2009: 28), estamos en un mundo cinematografiado, pues “(...) el individuo de las sociedades modernas acaba viendo el mundo como si éste fuera cine, ya que el cine crea gafas inconscientes con las cuales aquel ve o vive la realidad. El cine se ha convertido en educador de una mirada global que llega a las esferas más diversas de la vida contemporánea”. De ahí la necesidad de trabajar a partir del cine, a pesar de no dominar el "mundo de la pantalla"si se quiere reflexionar sobre el sentido mismo de la vida.

\section{La condición humana en la era global}

En nuestra aldea planetaria es preciso aceptar un nuevo paradigma que interprete la sociedad actual de acuerdo con las necesidades humanas fundamentales y la importancia de reelaborar las fronteras, es decir, los "límites" que los bienes de un sistema cada vez más globalizado nos impone. Así, Núñez (2002) sostiene la necesidad de proponer otras modalidades de articulación social, nuevas maneras de situar la responsabilidad personal en una sociedad desigual o de atender las responsabilidades públicas en una época de retracción social, sin dimitir de la obligación ética que implica el tener que luchar por una mayor igualdad en las oportunidades sociales y defender la diversidad cultural de nuestro planeta.

Una película como Babel del director mejicano Alejandro González Iñárritu ${ }^{4}$, nos permite profundizar sobre tres aspectos fundamentales en

\footnotetext{
${ }^{4}$ Para una mejor comprensión de este artículo, recomendamos el visionado de esta película. Ficha técnica: Título original: Babel. Director: Alejandro González Inárritu. País: USA Méjico. Año: 2006. Género: Drama. Guionista: Guillermo Arriaga. Productores: Alejandro González Inárritu, Jon Kilik y Steve Golin. Fotografía: Rodrigo Prieto. Música: Gustavo Santaolalla. Interpretación: Brad Pitt (Richard), Cate Blanchett (Susan), Gael García Bernal (Santiago), Elle Fanning (Debbie), Kôji Yakusho (Yasujiro), Rinko Kikuchi (Chieco), Adriana Barraza (Amelia), Nathan Gambie (Mike), Mohamed Akhzam (Anwar), Peter Wight (Tom), Harriet Walter (Lilly), Trevor Martín (Douglas), Mónica del Carmen (Lucía). Producción: Paramount Pictures. Duración: 143 minutos. Distribuidora: VIP.

Babel se estrenó en Cannes, en el año 2006. Obtuvo el Globo de Oro a la mejor película de
} 
esta línea: en primer lugar, tomando conciencia de la globalización como puesta en contacto de grupos humanos moldeados por culturas y lenguas diferentes; en segundo lugar, reflexionando en torno al progreso tecnológico, que no siempre satisface ni facilita aspectos tan humanos como la comunicación; y, por último, asumiendo la finalidad formativa del propio filme para interrogarnos sobre lo que supone el encuentro con el otro y la diversidad cultural.

Desde un punto de vista práctico, nos gustaría mostrar la enorme utilidad de una película como Babel para pensar en la formación de valores sociales y personales. A través de este filme, es nuestra misión ahondar en la preservación de ideales y aspiraciones que permanecen latentes en todos nosotros, y en nuestros alumnos en particular, con el fin de proceder a su impulso y puesta en práctica. Se trata de crear ambientes de convivencia que ofrezcan pautas de comportamiento para la vida, fomentando la reflexión y el análisis crítico de los valores y contravalores de nuestra época.

La tensión entre valor y contravalor es un conflicto entre cognición y emoción. "Varios estudios parecen indicar que la gente tiende a creer lo que quiere creer. Efectivamente, los experimentos demuestran que las personas son mucho más críticas a la hora de evaluar hechos que contradicen sus creencias que aquellos otros que respaldan lo que piensan. La selectividad sesgada de la mente crítica aparece ya en los primeros años de escolarización. Cuanta más educación tengan los ciudadanos, mejor podrán interpretar la información disponible de forma que respalde sus preferencias políticas predeterminadas. Esto es debido a que un mayor grado de conocimiento proporciona a la gente mas recursos intelectuales para una autorrealización que apoye sus interpretaciones erróneas inducidas por las emociones” (Castells, 2009:212).

La promoción de una nueva cultura académica que sea sensible a los nuevos hábitos culturales entronca con las directrices marcadas por el Espacio Europeo de Educación Superior ${ }^{5}$, a la vez que promueve nuevas

género dramático y fue candidata a seis premios Óscar, entre ellos a la mejor película y mejor director. Finalmente, consiguió el premio en la categoría de mejor banda sonora (Gustavo Santaolalla), en el año 2006. Esta película completa la -Trilogía de la muerte- de este director con Amores perros (Méjico 2000) y 21 Gramos (Méjico 2003).

${ }^{5}$ Remitimos al lector a la página web de la red de cooperación y colaboración universitaria de habla hispana y portuguesa, donde pueden localizarse todos los acuerdos, encuentros, informes y declaraciones oficiales en torno al Espacio Europeo de Educación Superior (EEES): [http://eees.universia.es], (5-10-2009).

Aunque la idea se plantea por primera vez en la Declaración de la Sorbona (1998), la construcción del Espacio Europeo de Educación Superior recibe un impulso decisivo con la Declaración de Bolonia, firmada el 19 de junio de 1999 por ministros con competencias en Educación Superior de 29 países europeos y que da su nombre al Proceso de Bolonia.

Se trata de un proyecto de carácter intergubernamental en el que participan las universidades, los estudiantes, la Comisión Europea y otras organizaciones, que se marcaron como meta el establecimiento de un Espacio Europeo de Educación Superior en el año 2010. 
formas de aprendizaje y denota una sensibilidad especial por el conocimiento en ámbitos educativos no formales (Sarramona, Vázquez y Colom 1998, Ortega 1999, Esteve 2003, Zabalza 2003, Caride 2005, Esteban 2005 y Bain 2006). Debido a ello, el cine viene a entrelazar nuestra mirada como espectadores, de donde surgen las emociones, los particulares sentimientos, así como las percepciones que nacen del espíritu crítico y de la subjetividad del juicio, con la búsqueda de nuevos estilos pedagógicos capaces de conectar con las nuevas generaciones y sus procesos de aprendizaje.

Insistimos, pues nos parece pertinente, en que los profesores que suscribimos este artículo venimos investigando e incidiendo en el valor potencial de la aplicación del cine como instrumento docente, potenciador de los procesos de aprendizaje y autoaprendizaje de los estudiantes ${ }^{6}$.

Nuestra respuesta quizás se acerque al trabajo habitual de reflexión e investigación sobre la pedagogía entendida en un sentido amplio, así como nuestra inclinación en formar a los futuros educadores haciendo de la época presente un tema pedagógico (Nassif, 1975). Educar no es sólo preparar intelectualmente, sino también considerar los valores morales. Por ello es fundamental profundizar en la globalización como un aspecto y dimensión que está definiendo y mediatizando, cada vez con más fuerza, todo cuanto acontece. Por supuesto, la economía, el comercio, el poder político-militar..., pero también la diversidad cultural, la diferencia tecnológica y cultural entre Norte y Sur, la comunicación y convivencia pacífica, sobre todo si existe la amenaza de que se impongan las culturas de las sociedades materialmente más ricas y poderosas mientras se intenta anular las culturas de las sociedades inferiores, a pesar de toda su riqueza humana (García Canclini 1995, Saramago 2000, Gimeno 2001, Morin 2001 Sampedro 2002, Mattelart y Neveu 2003 y Stiglitz 2006) ${ }^{7}$.

Su principal objetivo es el de aumentar la compatibilidad y comparabilidad de los distintos países miembros construyendo un espacio abierto en el que no existan obstáculos a la movilidad de estudiantes, titulados, profesores y personal de administración.

Los cimientos del EEES se encuentran en los objetivos alcanzados en la Declaración de Bolonia, que vertebran las líneas de acción a desarrollar, y que fueron ampliados en Praga (mayo 2001). Este proceso ha supuesto, a su vez, la puesta en marcha de un nuevo modelo docente centrado en el alumno en el que las Tecnologías de la Información y la Comunicación (TIC) adquieren un papel fundamental en la configuración de nuevos procesos de aprendizaje, espacios y comunidades virtuales de educación y creación y difusión de conocimiento a través de la red.

${ }^{6}$ En el libro El cine en educación: realidades y propuestas para su utilización en el aula, coordinado por Manuela Raposo (2009) se señala como el cine es un recurso válido y pertinente para la educación para toda la comunidad educativa.

${ }^{7}$ Dada que la globalización es en gran parte el "leiv motiv" de nuestra argumentación, y aceptando que hay diversas interpretaciones de este término, nos acercamos a la definición de Luis de Sebastián (2003) que la concibe como el resultado, todavía parcial y no predeterminado, de un proceso que tiende a unificar los mercados nacionales de bienes y servicios (y por «servicios» se entienden muchas actividades) en grandes mercados mundiales, a la vez que se introduce la lógica del mercado (privatización) en más esferas y campos de 
Es éste un aspecto fundamental en la formación de los futuros educadores sociales: cualquier persona, incluso la aparentemente más pobre y necesitada, nos puede aportar y enriquecer con su experiencia y conocimiento. Y tiene derecho a ser aceptada y comprendida a partir de su cultura. Como consecuencia, la aproximación, conocimiento, comprensión y reflexión en torno a las cuatro trayectorias vitales que se cruzan en Babel nos puede llevar a optimizar los modos de aprender de nuestros estudiantes, sus jerarquías de valores y sus análisis de las realidades sociales, teniendo en cuenta que todo ello puede ser comparable con las intervenciones educativas directas que acabarán desarrollando profesionalmente (McAdams 2003, Mallimaci y Jiménez 2006).

La metodología cualitativa que seguimos combina diversas estrategias grupales que propician el pensamiento, el conocimiento, el debate, la cooperación, el trabajo en equipo y los cambios de actitud (Pérez Serrano 2003 y Vallejos, Ortí y Agudo 2007). Se trata de promover una nueva cultura sensible a los hábitos culturales y a las nuevas formas de aprendizaje y generación de conocimiento en la sociedad actual, en cualquier espacio educativo. Enlaza, además, con la necesidad de otorgar la adecuada relevancia a las tecnologías de la información, la comunicación y los medios audiovisuales en la configuración de los actuales procesos de aprendizaje, elaboración, conocimiento y vinculación social ${ }^{8}$.

Un filme como Babel nos emplaza a la reflexión de los siguientes apartados que exponemos, a fin de que el alumnado:

- Advierta y perciba cómo la pertenencia a una cultura determinada nos lleva a captar el resto de culturas como inferiores; cuando en realidad existen muchas cosas en común (García Canclini 2004, Cobo 2005, Montealegre, 2007 y Touriñán 2008). Una tesis desarrollada por antropólogos tan importantes como Lévi-Strauss para combatir los prejuicios racistas fundamentados en una concepción que parte de la premisa de la inferioridad moral e intelectual de aquellos grupos humanos que no tienen la "piel blanca" y que encuentran su justificación en el hecho de que los éxitos de la civilización desarrollada, precisamente, por el hombre blanco, son superiores a los de las otras "razas". "Existen muchas más culturas humanas que razas

acción de la vida social de la humanidad. El proceso de globalización está siendo impulsado por tres grandes fuerzas: la integración económica de las empresas y los mercados, las innovaciones tecnológicas y una revolución política conservadora. Este proceso ha generado muchos cambios en el mundo de los negocios, pero también en el campo de la cultura, y en la manera como los hombres y las sociedades humanas se relacionan entre sí.

${ }^{8}$ Manuel Castells señala como en ocasiones la ingenuidad y las ansias de libertad se deben mantener a fin de detectar con un trabajo objetivo donde están las dimensiones que coartan la libertad de las personas o cómo éstas son mediatizadas por el poder de la educación y así escribe: “ Por consiguiente, mi análisis empírico será necesariamente incompleto, aunque espero estimular una analítica similar que estudie el poder en otras dimensiones como la cultura, la tecnologías, las finanzas, la producción o el consumo” (2009: 26). 
humanas, puesto que las primeras se mientan por millares y las segundas por unidades: dos culturas elaboradas por hombres que pertenecen a la misma raza pueden diferir tanto o más que dos culturas que dependen de grupos racialmente alejados [...]. Pero no podemos pretender haber resuelto el problema de la desigualdad de las razas humanas negándolo, si no se examina también el de la desigualdad -o el de la diversidad- de culturas humanas que, de hecho si no de derecho, está en la conciencia pública estrechamente ligado a él.” (Lévi-Strauss, 1993: 41-42). Así pues, según este autor, sólo examinando la diversidad cultural podremos encontrar el origen de los planteamientos racistas.

- Sea consciente de que la riqueza-pobreza de recursos materiales no está en estrecha relación con la calidad humana.

- Valore a cada persona como única e irrepetible, con su propia e inalienable dignidad.

- Estudie sobre la necesidad de no dejarnos dominar por una tecnología alienadora, que nos vuelva débiles e insensibles, a pesar del aparente apoyo que nos proporciona. Una meditación que también nos parece oportuno extender al ámbito pedagógico, en unos tiempos en los que el desarrollo de las tecnologías de la información y la comunicación parecen haberse asumido como un medio y un fin eficaz en sí mismo para satisfacer la educación permanente de los ciudadanos (Martín 2005 y Solé 2006).

- Comprenda que la globalización nos aproxima, pero también nos hace más dependientes, más vulnerables y más distantes.

- Se sienta en la obligación moral de humanizar nuestras sociedades para que podamos interactuar con otras y generar una riqueza cultural colectiva.

- Mejore la convivencia pacífica ante la diversidad cultural, haciéndole partícipe en el debate sobre las cuestiones que se plantean en el plano de las políticas públicas y la interculturalidad, un debate que, en las sociedades occidentales, permite distinguir dos grandes focos origen de la cuestión sobre la diversidad cultural en el campo de las políticas: por un lado, todo lo que concierne a la inmigración extranjera, presente en la película con el caso de la niñera mejicana y, por el otro, a la presencia de diversas comunidades culturales dentro de un mismo estado.

No es nuestro propósito desarrollar aquí todos estos aspectos, pero irán apareciendo, entrelazándose los unos con los otros a lo largo de este escrito. Las siguientes afirmaciones del director del filme cuando inició el rodaje orientan nuestra propuesta: "Lo mejor de Babel fue que empecé rodando una película acerca de las diferencias que separan a los seres hu- 
manos, las barreras físicas y el idioma, pero en el camino me di cuenta de que estaba haciendo una película acerca de lo que nos une, el amor y el dolor. Es muy posible que lo que hace feliz a un marroquí y a un japonés sea muy diferente, pero lo que nos hace sentir mal es lo mismo para todos" (González Inárritu 2007)9. Porque el cine, como nos dice Fuentes (2007), debe comunicar en un mundo incomunicado. Por eso llaman la atención las obras cinematográficas que atentan contra su naturaleza comunicativa y de masas, si éstas tratan precisamente el tema de la soledad y la ausencia de comunicación (intergeneracional, entre civilizaciones...). De eso nos habla Babel, de las esencias del cine, un medio donde el ser humano proyecta lo que acontece, unas veces de forma real y otras de forma ficticia, al descubrir todo lo que trasciende a lo largo de una vida.

\section{Una metáfora global}

En un planeta tan interconectado, el fenómeno de la globalización pone en evidencia la existencia de cotos cerrados y la ausencia de exclusividad. Hay civilizaciones que están preocupadas por su pérdida de identidad o porque su esencia se pueda diluir en un mundo globalizado. Quizás por ello, González Iñárritu señaló que la idea de rodar Babel fuera una causa directa de haber salido de su país natal y, también, del estado anímico en el que se encontraba en aquel momento. La obra se filmó en tres países. No responde a la pregunta ¿de dónde soy?, sino, ¿adónde voy? y dice al respecto: "Creo que compartimos esa angustia que produce estar fuera del país, pero al mismo tiempo esa perspectiva que se obtiene de estar fuera y de verte a ti mismo a través de los demás” (Rose 2007: 16).

Es evidente que la película forma parte de la realidad de la mundialización hipermoderna, aquella que nos remite a identidades que se confunden y a escenarios caleidoscópicos. Su director se inspira en múltiples referencias, va tejiendo un sincretismo cultural que, en el fondo, acaba siendo muy individualizado, pues aborda la incomunicación desde variadas perspectivas. Constatémoslo a partir de unos trazos sobre su argumento (López, 2009):

En Babel se narra la historia de dos niños hermanos, hijos de un humilde campesino, en el desierto marroquí. Como de costumbre, salen a cuidar su rebaño de cabras y, para protegerlas de los chacales, llevan un rifle Winchester, del calibre 270, proporcionado por su padre, que lo acababa de comprar a cambio de 500 dirhans y un cabrito. Desde la aventura y la inocencia, deciden ver hasta dónde llega el arma y comprobar si es cierta la afirmación del vendedor: su alcance de tres kilómetros. Pero la bala llega más lejos de lo imaginado, se introduce en un autobús de turistas que circulaba por el paisaje rocoso y arenoso y termina hiriendo a una pasajera norteamericana. En un instante, colisionan las vidas de cuatro grupos de perso-

${ }^{9}$ Consultar, al final, Medios electrónicos. 
nas separadas por tres continentes (África, América y Asia): una pareja estadounidense, inmersa en la incomunicación ante la pérdida de un hijo recién nacido, está atrapada en medio de un accidente que se escapa del control de todos; una adolescente japonesa sordomuda que intenta convivir con su padre, recientemente viudo, y que buscan puntos de conexión común hacia el diálogo; una niñera mejicana que, sin permiso, cruza la frontera con dos niños norteamericanos, hijos de la pareja de turistas, para asistir a la boda de su hijo; y una familia marroquí (la de los niños que disparan el rifle) anclada en la rudeza del trabajo duro y los escasos medios de subsistencia.

Todos estos personajes tienen un hilo conductor común, el azar, pero también la incomunicación, la soledad y el dolor. El director los enlaza por medio de un hecho fortuito (la venta del rifle del padre de la muchacha japonesa sordomuda que acaba provocando el accidente de los turistas norteamericanos y el forzado cambio de planes de la niñera mejicana que se ocupa de sus hijos), una expresión más de la globalización.

Ninguno de los cuatro grupos descritos se va a conocer, a pesar de la repentina e improbable interrelación entre ellos; siempre estarán aislados, debido a la propia incapacidad de comunicarse con su entorno, aun existiendo medios de comunicación (teléfono, radio, TV, móvil...) que remiten a un contexto tecnológico que, en principio, debería propiciarlo. Sobre el relato, Babel no es una trama única, con un planteamiento, un desarrollo y un final, tal y como establece el guión básico hollywoodiense. Nos encontramos ante cuatro historias encadenadas con vida propia. No hay unidad de acción, heredada de la vieja regla básica que distinguía entre acción principal y acciones secundarias. En esta película, lo secundario es tan importante como lo principal. Toda su urdimbre nos embauca desde principio a fin, no pasa desapercibida, ni nos deja impasibles. Nos incita a continuas reflexiones. Se refuerza la idea de la interconexión del mundo actual (el efecto mariposa); a pesar de que seamos incapaces de comunicarnos personalmente. De alguna forma u otra, todos influimos en nuestras propias vidas y en las de los otros. En la película, cuatro escenarios simultáneos se interfieren sin saberlo, cruzan trayectorias vitales que acaban envueltas en el desconcierto, que son destrozadas y arrastradas por el azar, pero que tienen un nexo común, la incomunicación y el sufrimiento humano. Ya lo vimos en Short cuts (Vidas cruzadas), de Robert Altman (USA 1993) ${ }^{10}$, y en Crash (Coli-

\footnotetext{
${ }^{10}$ Short cuts aborda las vidas de hombres y mujeres, residentes en Los Ángeles, que intentan amoldarse al mundo laboral: policías, maquilladoras, conductores, cantantes de jazz, médicos, especialistas en sexo por teléfono, comentaristas de televisión, camareras... se van cruzando por el camino, ignorando los dramas que tienen lugar paralelamente. Sin ser la primera en la historia del cine, Short cuts se convirtió en paradigma de las películas compuestas por historias independientes que se entrecruzan en algún momento del relato -a veces de forma casual, o bien a causa de algún acontecimiento que afecta a todos los personajes-.
} 
sión), de Paul Aggis (USA 2004) ${ }^{11}$. Una propuesta de cine coral que, a partir de cuatro historias que convergen entre sí, mediante vínculos muy lejanos, acaba mostrando un vasto cuadro capaz de condensar todo un planeta. Esta heterogeneidad estructural y narrativa permite reflejar la fragmentación del mundo y las segmentaciones sociales que alberga: una familia marroquí atada a la tradición y los medios básicos de subsistencia; un matrimonio norteamericano que se suma a un turismo exótico masificado en busca de nuevos alicientes para sus vidas, después del trágico acontecimiento; un pueblo aislado del Marruecos más profundo cuyos habitantes acaban socorriéndoles de forma altruista y solidaria; una mejicana en situación ilegal en Estados Unidos que se desvive por el cuidado de unos niños; y una adolescente japonesa sordomuda rodeada de tecnología, modernidad y sofisticación que debe hacer frente a su soledad afectiva ante el suicidio de la madre y las dificultades para comunicarse con su padre.

Sin embargo, y aunque pueda parecerlo, nadie habita en un estadio de superioridad en ninguna de las culturas expuestas (marroquí, americana, mejicana y japonesa). Cada vez más, en esta era global, dependemos y necesitamos de los demás. En la película este efecto se refleja en diferentes escenas; en el caso concreto de Richard (el turista norteamericano), depende totalmente del medio social y cultural del que proviene el guía y la tradición del pueblo marroquí donde llevan a su esposa para auxiliarla. Observamos en el drama de esta pareja un proyecto de convivencia para nuestro mundo global, representado en la actitud comprensiva y comprometida del guía hacia Richard; tal vez reflejando que las personas aparentemente más pobres tienen su papel en la vida de los demás. Probablemente, este guía no sólo pertenece a una cultura materialmente inferior, razón por la que despierta tantos prejuicios, sino que se muestra más sensible a las necesidades de los otros y más capaz de esforzarse en socorrerlos sin esperar nada a cambio cuando comparamos su actitud al egoísmo de los otros turistas del autobús, invadidos por el pánico ante posibles altercados y deseosos de volver de inmediato a su lugar de origen sin preocuparse por la viajera accidentada.

Se plantea, así, el sentido de nuestra existencia en una aldea global donde todo está interconectado. Es por ello que Babel indaga en lo personal y en lo social. Describe con realismo las barreras (físicas, socioculturales, educativas, lingüísticas, ideológicas, emocionales...) que separan a los se-

\footnotetext{
${ }^{11}$ Crash (Colisión) sigue la pista del encuentro fugaz entre un grupo de personajes de diferentes razas, que luchan por superar sus miedos a medida que entran y salen de las vidas de los demás: un detective de policía negro con una madre drogadicta y un hermano desaparecido; dos ladrones de coches que teorizan continuamente sobre la sociedad, el ocupado fiscal del distrito y su irritable esposa; un veterano policía racista (que cuida de su padre enfermo) que no gusta a su joven e idealista compañero, un exitoso director de televisión y su altiva esposa; un inmigrante persa que compra un arma; un cerrajero hispano y su pequeña hija, etc. En la zona gris entre el blanco y el negro, donde todo el mundo es víctima y agresor, todos colisionarán durante las próximas 36 horas. Crash se convierte, así, en un intenso drama que retrata sin tapujos los conflictos raciales y sus consecuencias.
} 
res humanos a pesar de convivir en un mismo planeta (Touraine 2000, Meirieu 2002, Moreno 2004, Jarne 2006 y Córdoba y Cabero, 2009). Se palpa la existencia de una gran fractura entre los pueblos marroquíes que habitan sus tierras y los turistas pudientes que las visitan. Pero también, si seguimos a la joven Chieko (la adolescente japonesa), percibimos la desvinculación existente entre los sordomudos y aquellos que oyen y hablan en un mundo marcado por el ruido. El otro es el extranjero, el que no es el prójimo porque no es próximo. Ante esto, comprobamos la dificultad para cumplir el mandato bíblico “amarás a tu prójimo como a ti mismo”. En esta obra sólo se pondrá en práctica cuando el prójimo se adapte y se someta, a pesar de las discapacidades. Tal y como sucede en el caso de Amelia, la inmigrante mejicana, que sólo logra encontrar el cariño, la acogida y el amor incondicional en brazos de su hijo, mientras que de aquellos a quienes ha cuidado, servido y desvivido durante años, los hijos de su amo, tan sólo consigue que no levanten cargos en su contra.

\section{Geografías de la incomunicación}

En un lado del planeta, Marruecos. Una pareja de turistas norteamericanos sin posibilidad de articular palabra salvo para lanzarse reproches. La mujer apenas necesita de la voz para mostrar el inevitable dramatismo de la situación inesperada. Un rostro que define las múltiples caras de la amargura, primero de la infelicidad, tras la que vendrá el dolor. En su personaje no hay lugar para la alegría, ni siquiera para la despreocupación más ligeramente distendida. Al dolor le seguirá el pánico por una situación incontrolada, y todo ello en una sucesión de registros interpretativos que se acercan a la perfección. Ocurrido el accidente, su marido sigue sin poder expresarse para salvarla, herida gravemente, por ubicarse en una sociedad rural, pobre, y cerrada, y por tratar, vía telefónica, con unos diplomáticos atenazados por el pavor de desencadenar fuerzas insospechadas. Sin embargo, las dificultades por hacerse entender harán desaparecer este ambiente hostil. El peligro físico que les envuelve obligará a confiar en personas que, por su cultura y apariencia, les provocarían desconfianza y rechazo, pero que terminarán siendo su salvación. Con toda humildad y apoyo les darán una verdadera lección de humanidad frente al egoísmo, la reticencia y la insolidaridad de los otros viajeros del autobús, partícipes de su misma cultura.

Es evidente que la pareja no desea otra cosa que recomponer su convivencia, volver al entendimiento y a la armonía; y esa es la grandeza de este filme. Hoy, el reencuentro más íntimo, el de siempre, el más cercano, está en una comunión global interconectada. En este caso, en medio de una comunidad marroquí rural, aislada en su propia miseria.

Al otro lado del globo está Japón, que pasa por ser el país con la más alta e innovadora tecnología mundial. Allí, un empresario vive abrumado por el recuerdo de su mujer recién fallecida y una hija adolescente sordomuda, Chieko, recluida en sí misma, en actitud rebelde, con quien 
apenas logra entenderse. Una sociedad, por otra parte, estrepitosa que encierra aún más a esta chica en su silencio interior. Chieko simboliza el prototipo de la soledad, la incomunicación y el sufrimiento; pero si olvidamos su discapacidad, podríamos confundirla con cualquier otra adolescente influida por su actual cultura juvenil. En todo caso, en su dificultad extrema para expresarse, queda reducida a su dimensión meramente corporal. Para salir de su aislamiento y sentirse adulta necesita entregarse a un hombre cualquiera. Si su organismo no escucha, porque es sorda, hace que el otro escuche su cuerpo: así son sus insinuaciones sexuales al dentista, a los jóvenes en la cafetería o desnudándose ante el policía, en claros síntomas de una inmensa soledad. Sin embargo, ¿podemos ver en su intento de salir de ese silencio omnipresente, a través de la comunicación más primaria del sexo y las drogas, el comportamiento común de cualquier adolescente de este mundo globalizado? Comprobaremos como, al final del filme, encontrará el afecto y comprensión de su padre, algo primordial para su autoestima y realización personal.

Chieko pretende participar de un gozo que carece; quiere arrebatárselo al otro, imponérselo a veces, hasta con malos modos, como la escena deportiva; por eso la rechazan: no por su discapacidad, como ella imagina, sino por su modo de actuar. Pero, ¿cómo puede expresarse si no habla? Ella entra en un laberinto: como sordomuda, ofrece su cuerpo sobrepasando los límites de la corrección moral y el orgullo femenino, rompiendo con cualquier sutileza, vergüenza y juicios de valor. Sin embargo, por su forma de ofrecimiento la evitan, y también la marginan por su sordera. La joven quedaría condenada a vivir exclusivamente entre los suyos. Así nos lo muestra el director de la película en las escenas de la discoteca o en ese paseo sin banda sonora, ni ruidos, inmersa en el silencio, con imágenes tomadas a gran velocidad. Y, en contraste, las escenas al son de la música más extravagante, de una noche loca en Tokio, a la vez que leemos, "Las luces más brillantes en la más oscura noche”.

A pesar de estas situaciones, no consiguen desbloquearla y, al término de la película, se abre una puerta a la esperanza en la carta que la joven entrega al policía, cuyo mensaje nunca conoceremos. Quizá nos diga algo esa última escena tomada desde el balcón del rascacielos, donde desnuda, pálida e invadida de tristeza está mirando ese impactante y sobrecogedor Tokio nocturno. Puede que la salve la llegada de su padre, cuando todo parece indicar que estaba a punto de suicidarse. Es el colofón de la obra, donde se brinda un mundo de posibilidades a la historia y permite dudar de todo lo que hemos visto para recrearnos, así, en los abiertos, múltiples y variados finales posibles.

Mientras, Yasuhiro y Cheiko, padre e hija, vivían ignorantes de las consecuencias de unas vacaciones del primero, durante un anterior safari por el Atlas marroquí, podían ser la causa de un terrible desenlace que pone al límite a varias personas. Muerte, esa palabra que ellos conocen bien y que padecen en su desierto interior; sentimiento que han vivido en su propia carne con la pérdida de su ser más querido. 
En otro tercer lugar de la esfera terrestre, los hijos de la pareja norteamericana son cuidados, en California, por una mejicana ilegal, Amelia, una mujer llena de bondad, dispuesta a dar lo mejor de sí por los niños. Lleva dieciséis años sirviendo. Precisamente ese día, el del fatal accidente, se casa su hijo. En su cultura, la madre no puede faltar a tan célebre acontecimiento. Como no consigue a nadie que la reemplace, decide llevárselos a Méjico en el coche de su sobrino Santiago. En otras ocasiones, la frontera se pasa sin dificultad; pero la sociedad mejicana vive lindando con un país sensorizado, con los mecanismos más sofisticados, repleto de alambradas y muros insalvables. Aunque cada año miles de inmigrantes ilegales cruzan la frontera, son muchos los que dejan allí su vida.

Una vez celebrada la boda, Santiago, el sobrino de Amelia, los lleva en el automóvil de regreso, casi al amanecer. Conduce bebido y desencadena una tragedia, abandonando a su tía y a los niños en el desierto norteamericano, tan duro como el marroquí, donde están atrapados los padres de los niños y donde malviven, día a día, los causantes originarios del suceso. Amelia será mal interpretada ante la policía por su actuación y sólo recibirá incomprensión y un trato deshumanizado, en las antípodas de su forma de ser y comportarse. Y es ese desierto, recurrente a lo largo de la película, a modo de metáfora, lo que devasta el interior del ser humano: el desierto del Sahara, el desierto norteamericano, en sus valiosas y diversas tonalidades cromáticas. Pero son lugares de excepcional dureza, por más que no deje de sorprendernos su inusual y bella característica; y el desierto de la soledad, carente de colores vivos, como el que define a una sociedad del futuro ya presente.

\section{Consideraciones finales}

La globalización se presenta como un destino inevitable que nos afecta a todos, independientemente de donde vivamos o lo privilegiados y marginados que seamos -tal y como sugiere Anthony Giddens (2003) - si bien las consecuencias no son las mismas para unos o para otros. Frente a una época de relativismo moral llega la disciplina bíblica, readaptando mitos como el de la Torre de Babel, para recordarnos que estamos llamados a entendernos, a pesar de las fronteras que nos separan: geográficas, lingüísticas, socioculturales y educativas, físicas o emocionales. "Por eso se llamó Babel, porque allí confundió Yahvé la lengua de la tierra toda, y de allí los dispersó por el haz de toda la tierra” (Génesis 11, 9). La globalización nos hace ver nuestra pertenencia a un único género humano, la dependencia de unos y de otros, pero con una tendencia inevitable a enfrentarnos porque no somos conscientes de que buscamos lo mismo y que lo encontraríamos más fácil y plenamente si nos ayudásemos desde la confianza, en lugar de oponernos por estar instalados en el recelo.

Las circunstancias que marcan nuestros destinos dependen en gran medida del azar, de acciones que desconocemos su desenlace y que, sin embargo, pueden influir decisivamente en nuestra vida. Por eso, la película 
que hemos analizado es una elocuente metáfora de estos tiempos. El azar juega un papel fundamental en la vida de estos personajes, ya no sólo porque conecta las cuatro historias, sino porque aparece como causa principal del infortunio y de un futuro que no pueden controlar. En el espíritu de estas víctimas queda el miedo, compañero inseparable de la frágil condición humana, puesto que ninguno de ellos puede proyectar su porvenir en el futuro más inmediato. Sin duda, es el estado emocional de los millones de damnificados de la crisis planetaria que estamos sufriendo. Nadie sabe a ciencia cierta cómo se van a desencadenar los hechos que los arrastran y la incertidumbre lleva al temor. Todo acaba teniendo la extraña apariencia de pertenecer al accidente o a la fatalidad. Como en las mejores tragedias griegas, es inevitable pensar en el protagonista, que gracias a los avances de la cultura y la técnica griegas se consideraba superior a los bárbaros y pretendía dominarlo todo. Por eso, suponía un reto intelectual y moral comprender y aceptar la desgracia irremediable. Esquilo recurría al designio superior de los dioses; Sófocles, al carácter y las pasiones de los humanos; y Eurípides simplemente admitía el azar.

Sin embargo, aceptar la globalización como destino puede ocultar lo que se esconde detrás de los procesos y “efectos globales” involuntarios e imprevistos que provoca. Tal y como nos advierte Zygmunt Bauman (2001), si las consecuencias globales responden a una causalidad azarosa, las acciones, iniciativas y empresas locales que puedan provocarlas desaparecen. De esta manera, se hace pasar una cosa producida por el hombre por una situación supuestamente natural e inexorable ante la que no hay nada que hacer. No queda espacio, entonces, para la reacción individual o colectiva, un hecho sobre el que pretende hacernos analizar la película.

El filme también nos muestra otro de los problemas que más dividen el mundo actual: la aparición de una vasta brecha tecnológica (Bernal 2009: 82). El contraste entre el pueblo marroquí y la ciudad hipertecnificada de Tokio es un vivo ejemplo que apunta hacia uno de los mayores retos a los que se enfrenta hoy la sociedad global. Éste es el escenario planetario y, por lo tanto, su mayor amenaza. Tal y como Paul Kennedy (1993) anticipó en su célebre ensayo -si no se consigue evitar que esta falla tecnológica estalle- ahogará todos los demás problemas del siglo XXI, por lo que no sólo es necesaria, sino rigurosamente urgente, una reflexión que derive en políticas capaces de decidir sobre un cambio en las prioridades culturales; algo que sólo resultará probable si adoptamos una visión global y la voluntad mínima para articular principios universales más amplios.

González Iñárritu nos alerta sobre los riesgos y las dinámicas inevitables que esta situación está generando, como son los fuertes movimientos migratorios -encarnados en la cuidadora mejicana- que se están viviendo en las últimas décadas cuestionando, así, los modelos de integración cultural en las sociedades del capitalismo avanzado. Por una parte, visualizando las razones que fuerzan a grandes masas de población a abandonar sus países de origen; por otra, la dificultad de las sociedades receptoras a la hora de desarrollar políticas de integración, sin caer en un tratamiento policial 
de la migración y en los prejuicios sociales (Dumont 2008). Aunque también es una forma de introducir grupos humanos en otras culturas: los turistas en medio de Marruecos; los mejicanos trabajando en California; los niños americanos en la boda mejicana; la tradición japonesa ante un entorno altamente tecnificado, etc. que requiere la continua actitud de una adecuada asimilación.

Las redes que comunican una sociedad globalizada son tejidas por la movilidad sin restricciones (sobre todo de capitales, bienes y servicios), pero también de ideas y seres humanos. La libertad de movimiento se constituye, así, en el eje clave sobre el que se establecen las jerarquías, las divisiones y las polaridades de la nueva formación social global. Sin embargo, la libertad de movimientos se distribuye de una manera desigual entre los diferentes individuos y grupos sociales, hasta el punto de que la movilidad para unos significa la inmovilidad para los otros. Babel lo escenifica inteligentemente si seguimos el viaje de los turistas norteamericanos. El itinerario del autobús por parajes remotos tiene sentido si los viajeros pueden ver y reconocer postales fijas durante el trayecto: unas veces ofrecidas por el propio paisaje y la naturaleza que lo configura; en otras, un poblado, el encuentro con un atisbo de civilización, la tribu que colorea y da un toque exótico al entorno, los seres humanos arraigados en asentamientos centenarios y las tradiciones ancestrales que impregnarán de autenticidad la visita del viajero.

La distribución diferencial de la movilidad, tal y como nos advirtió Bauman (2001) significa que unos pueden adquirir la condición de "globales" y otros sólo la de "locales"; unos se hacen móviles, mientras que otros se quedan estáticos en su localidad; unos pueden moverse libremente, y otros, como Amelia, arriesgan sus vidas si lo intentan. El director de la película recrea el hecho de que existen unos sujetos activos en la globalización, mientras que otros sólo pueden ser sujetos pasivos. Son sujetos activos los que tienen capacidad para consumir, en este caso la pareja norteamericana que ha podido adquirir un paquete turístico hacia Marruecos (los sujetos móviles que contemplan el mundo). La niñera de sus hijos o la población autóctona marroquí, en tanto que "consumidores fallidos", se convierten en el reverso de la misma moneda, representando al sujeto pasivo inmovilizado; es decir, al pobre y, por lo tanto, al excluido. González Iñárritu señala, de esta manera, que la identificación de las personas en un mundo global no se puede separar del análisis de los mecanismos de producción y distribución de recursos materiales y simbólicos que, al asignar diferentes poderes y responsabilidades, los convierten en sujetos activos y pasivos.

El choque cultural que presenciamos en el filme entre el grupo de turistas y los habitantes del poblado marroquí es una muestra evidente de la falta de unidad de los efectos de los procesos de globalización. También, de la tensión entre dos órdenes simbólicos que se contraponen: Occidente versus Oriente. En la actitud de los turistas, que desconfían de la población local, podemos reconstruir el proceso con el que Occidente mira a Oriente 
y define el rostro del otro, que halla bajo las formas ajenas a su identidad, sea cual sea, su especificidad cultural. El conflicto que se nos expone tiene como base el miedo al extraño; por ello aparecen mecanismos de exclusión, a menudo marcados por formas de intolerancia y violencia. Sólo cuando se logra mirar más allá de los propios estereotipos culturales se conecta y, por lo tanto, se comunica con la humanidad del otro.

La intercomunicación se establece si hay un destino compartido. En Babel lo hace posible el sufrimiento humano: el de la pareja norteamericana con el guía; la curandera y el veterinario marroquíes que los socorren al borde de un trágico final; el de la adolescente japonesa con un policía familiarizado con el horror; en definitiva, el encuentro con el valor de las personas que no han perdido su humanidad y sus buenos sentimientos hacia otro ser humano y que pueden ser, en un momento dado, nuestra salvación.

El sufrimiento compartido en esta película nos lleva a sentirnos personas. Enlacemos las escenas en primeros planos, donde las manos simbolizan la clave de la comprensión, el afecto y la solidaridad entre los humanos, un modo de expresar las cuatro historias que componen esta recreación: la pareja de viajeros se abraza, se besa y unen sus manos en medio del dolor y la incomunicación; la cuidadora inmigrante, desesperada, busca consuelo y comprensión entre sus propias manos al sentirse malentendida por la policía; el protagonista, a punto de partir hacia su país en el helicóptero con su esposa herida, quiere gratificar económicamente al guía marroquí, y se despiden apretando sus manos; el policía y la adolescente estrechan las suyas disculpando la escena que sólo busca un sutil entendimiento; y finalmente, el abrazo entre padre e hija en la terraza del rascacielos de Tokio, una muestra de la fragilidad que nos rodea y la necesidad de encontrarnos con nosotros mismos (Bauman 2008). En suma, un conjunto de escenarios geográficos y humanos inmersos en la globalidad del planeta y necesitados mutuamente.

El espectador sólo puede asistir, impávido, al sufrimiento del padre marroquí ante la injusta muerte de su niño. Siempre el más débil parece más proclive a la desgracia. También repara en los distintos métodos policiales según sea el país al que pertenezcan. Una heterogeneidad que lleva a la inevitable compasión del observador.

La música se mezcla entre las sensibilidades de las distintas culturas expuestas y con las diferencias de los paisajes que acogen las historias. Una amalgama de sonidos preeminentes y definitorios de la variedad basada en la tradición y en sus diversas evoluciones. Distintos estilos, instrumentos a veces imposibles, ruidos electrizantes. El sonido se adapta, también, a la multilateralidad.

Lo intercultural se acepta como una consecuencia amplia de nuestras innatas distinciones. El mundo es diverso, heterogéneo, pero profundamente desigual. Podemos entender un paisaje inesperado, la sociedad que 
lo habita y la cultura en la que se recrea, los distintos despertares a la vida desde la adolescencia y las múltiples caras y características que tiene el dolor, pero necesitamos tiempo para asimilar esa adaptación. La grandeza humana, independientemente de la condición, hace más proclive la comunicación entre personas. Los sentimientos, los buenos principios, sólo arraigan en la comúnmente escondida sensibilidad. El simbolismo de la sangre, presente en todas las culturas, nos aborda como el cenit de toda situación dramática. La insultante velocidad de las malas noticias y su inevitable, también malintencionada, manipulación en un viaje que desvirtúa la esencia y la veracidad de las mismas.

Las consecuencias de lo global, la pluralidad del mundo, sus flujos migratorios y la diversidad, demasiado extensa para lo que nos es acostumbrado, constituyen un entramado que reclama un esfuerzo por buscar puntos convergentes, por el desarrollo y la asunción de una ética que enseñe a asumir la realidad de lo que nos es extraño, pero que irrumpe en nuestro camino, tarde o temprano, en forma de situaciones singulares que sólo se pueden afrontar desde la vigencia tangible de valores imperecederos. Justo esos valores inherentes a los estudios de Educación Social, desde una visión crítica, comprometida, sin caer en los discursos moralizadoras y las intenciones redentoras.

Los estudiantes de Educación Social, partícipes en estos procesos de aprendizaje sobre historias de vida, motivados por seguir preparándose profesionalmente en estos ámbitos de intervención socioeducativa, estimaron esta experiencia llevada a cabo sobre el análisis de Babel y subrayaron la necesidad de potenciar estas situaciones creadoras de conocimiento con el cine. Consideraron la necesidad de comunicarse para analizar y contrastar sus vivencias sentimientos y afectos, a través del cine fórum, un modo de valorar y respetar los conocimientos, sentimientos y actitudes suscitados en el aula.

Todo esto nos será de gran utilidad si nos sumergimos en la reflexión de las técnicas específicas del mundo del celuloide (guión, escenas, planos, movimientos de cámara, diálogos, luz, música, efectos especiales,...) que, como en el caso que nos ha venido ocupando, nos ha brindado el conocimiento de los múltiples elementos ejemplarizantes que contiene esta película. 


\section{Bibliografía}

Aparici, R. y García Matilla, A. (2008), Lectura de imágenes en la era digital, Ediciones de la Torre, Madrid.

Bain, K. (2006), Lo que hacen los mejores profesores universitarios, Universidad de Valencia, Valencia.

Bauman, Z. (2001), Globalització. Les conseqüències humanes, Edicions de la Universitat Oberta de Catalunya, Barcelona.

Idem (2008), Amor líquido. Acerca de la fragilidad de los vínculos humanos, Fondo de Cultura Económica, Madrid.

Bergala, A. (2008), L'Ipotesi cinema. Piccolo trattato di educazione al cinema nella scuola e non solo, Cineteca Bologna, Bologna.

Bernal, A. (2009), “Cibermundo y educación. Bosquejo de un nuevo marco formativo en contextos postmodernos”, en Teoría de la Educación. Revista Interuniversitaria, vol. 21, No. 1: 71-102, Universidad de Salamanca, España.

Buitrago, M. J. y Pereira, C. (2007), Educar para la ciudadanía. Los valores del ocio y el tiempo libre, Aljibe, Málaga.

Caride, J. A. (2005), Las fronteras de la Pedagogía Social: perspectivas científica e histórica, Gedisa, Barcelona.

Idem (coord.) (2009), Los derechos humanos en la educación y la cultura. Homo Sapiens Ediciones, Rosario-Santa Fe-Argentina.

Castells, M. (2009), Comunicación y poder, Alianza, Madrid.

Cobo, J. M. (2005), Otro mundo es posible. Propuesta de una utopía para el siglo XXI, Biblioteca Nueva, Madrid.

Córdoba, M. y Cabero, J. (coords.) (2009), Cine y diversidad social. Instrumento práctico para la formación en valores. Eduforma, Sevilla.

Cuenca, M. (2005), Ocio solidario. La experiencia en grupos de jóvenes y jubilados, Universidad de Deusto, Bilbao.

Dumont, G. F. (2008), “La nueva lógica migratoria del siglo XXI”, en Debats. Migraciones, No. 99: 70-78. Valencia, España.

Escámez, J., García, R., Pérez, C. y Llopis, A. (2007), El aprendizaje de valores y actitudes. Teoría y práctica, Octaedro-OEI, Barcelona. 
Esteban, V. (edit.) (2005), El Espacio Europeo de Educación Superior, Universidad Politécnica de Valencia, Valencia. España.

Esteve, J. M. (2003), La tercera revolución educativa. La educación en la sociedad del conocimiento, Paidós, Barcelona.

Ferrés, J. (2007), “La competencia en comunicación audiovisual: dimensiones e indicadores”, en Comunicar, No. 29:100-107. Huelva. España.

Fuentes, C. (2007), Babel, en El País, Cultura. 25, de febrero, 55. Madrid.

García Canclini, N. (1995), Consumidores y ciudadanos. Conflictos multiculturales de la globalización, Grijalbo, D. F. México.

Idem (2004), Diferentes, desiguales y desconectados. Mapas de la interculturalidad, Gedisa, Barcelona.

Giddens, A. (2003), Un mundo desbocado. Los efectos de la globalización en nuestras vidas, Taurus, Madrid.Gimeno, J. (2001), Educar y convivir en la cultura global, Morata, Madrid.

Giroux, H. A. (2003), Cine y entretenimiento. Para una crítica política del filme, Paidós, Barcelona.

González, J. F. (2004), Aprender a ver cine, Rialph, Madrid.

Gubern, R. (1988), Mensajes icónicos en la cultura de masas, Lumen, Barcelona.

Gutiérrez, M. C., Pereira, Ma C. y Valero, L. F. (2006), "El cine como instrumento de alfabetización emocional”, en Teoría de la educación. Revista Interuniversitaria, vol. 18: 229-260, Universidad de Salamanca, España.

Jarne, N. (2006), “El cine en Hispanoamérica hoy”, en Making Of, No. 40: 5-15. Barcelona.

Josso, M. C. (2000), La formation au coeur des récits de vie. Expériences et savoirs universitaires, L'Harmattan, Paris.

Kennedy, P. (1993), Hacia el siglo XXI, Plaza \& Janés, Barcelona.

Hernández, M. (2008), Babel. Una lectura sobre el caos, la globalización y el dolor, en Alarcón, L. A., Blázquez, M. J. y otros, Cine, salud y nuevos entornos. Mira local, piensa global, Gobierno de Aragón, Zaragoza, 59-89.

Hueso, A. L. (1998), El cine y el siglo XX, Ariel, Barcelona.

Lévi-Strauss, C. (1993), Raza y cultura, Càtedra, Madrid. 
Lipovetsky, G. y Serroy, J. (2009), La pantalla global. Cultura mediática y cine en la era hipermoderna, Anagrama, Barcelona.

López, J. (2009), Teoría del guión cinematográfico. Lectura y escritura. Síntesis, Madrid.

McAdams, D. P. (2003), Identity and Life Story, en Fivush, R. y Haden, C. A. (eds.), Autobiographical Memory and the Construction of a Narrative Self. Developmental and Cultural Perspectives, Lawrence Erlbaum Associates Inc, Londres, 187-207.

Mallimaci, F. y Giménez, V. (2006), “Historia de vida y métodos biográficos”, en Vasilachis, I., Estrategias de investigación cualitativa, Barcelona, Gedisa, Barcelona, 175-212.

Martín, A. (2005), "La digitalización de la enseñanza o el sueño del aprendiz electrónico” en Revista de Teoría de la Educación, Volumen 17: 157184, Universidad de Salamanca.

Martínez-Salanova, E. (2002), Aprender con el cine, aprender de película. Una visión didáctica para aprender e investigar con el cine, Grupo Comunicar Ediciones, Huelva.

Mattelart, A. y Neveu, E. (2003), Introduction aux études culturelles, La Découverte, Paris.

Meirieu, P. (2002), Repères pour un monde sans repères, Desclée de Brouwer, Paris.

Molina, J. G. (2003), Dar (la) palabra: deseo, don y ética en educación social. Gedisa, Barcelona.

Montealegre, J. (2007), “Identidad y representaciones en un mundo globalizado”. Polis, No 18, Santiago de Chile.

Moreno, A. (2004), Valores Mexicanos en Estados Unidos. De Foreign Affair, En Español, Abril-Junio.

Morin, E. (2001), Los siete saberes necesarios para la educación del futuro, Nueva Visión, Buenos Aires.

Nassif, R. (1975), Pedagogía de nuestro tiempo, Kapesluz, Buenos Aires.

Núñez, V. (coord.) (2002), La educación en tiempos de incertidumbre: las apuestas de la Pedagogía Social, Gedisa, Barcelona.

Ortega, J. (1999), “Educación Social especializada, concepto y profesión”, en Ortega, J. (coord.), Educación Social especializada, Ariel, Barcelona. 
Pereira, C. (2005), “Cine y Educación Social”, en Revista de Educación, No. 338: 205-228, Madrid.

Pérez Rubio, P. (2004), El cine melodramático, Paidós, Barcelona.

Pérez Serrano, G. (2003), Pedagogía Social. Educación Social: construcción científica e intervención práctica, Narcea, Madrid.

Prats, L. (2005), Cine para educar, Belacqua, Barcelona.

Raposo, M. (Coord.) (2009), El cine en educación: realidades y propuestas para su utilización en el aula, Andavira Editora, Santiago de Compostela.

Rose, C. (2007), “La noche de los Gotham” en Letras Libres, Extra de cine mexicano, No. 67: 14-20.

Sáez, J. (2009), “El enfoque por competencias en la formación de los educadores sociales: una mirada a su caja de herramientas”, Pedagogía Social. Revista Interuniversitaria, No. 16: 9-20, Universidad Pablo de Olavide, Sevilla, España.

Sampedro; J. L. (2002), El mercado y la globalización, Círculo de Lectores, Barcelona.

Saramago, J. (2000), La caverna, Alfaguara, Madrid.

Sarramona, J., Vázquez, G. y Colom, A. J. (1998), Educación no formal, Ariel, Barcelona.

Sebastián, L. de (2002), Un mundo por hacer: claves para comprender la globalización, Trotta, Madrid.

Solé, J. (2006), “La institució escolar davant el discurs de les Tecnologies de la Informació i la Comunicació” en Revista TEXTOS de la Cibersociedad, 11. Temática variada. Disponible en http://www.cibersociedad.net, (5-102009).

Solé, J., Gómez, M. y Gimeno, X. (2007), “Tres propuestas formativas a través del cine. Sleepers como estudio de caso”, en Universitas Tarraconensis, Revista de Ciències de l'Educació, III época: 151-159. Universidad Rovira i Virgili, Tarragona, España. Edición electrónica disponible en: http://pedagogia.fcep.urv.cat/departament/publicacions/ univ_tarraco/descarrega.htm. (2-11-2009).

Stiglitz, J. (2006), Making globalization work, Russ Juskalian, USA.

Talens, J. y Zunzunegui, S. (1995), Rethinking film history. History as narration, Episteme, Valencia. 
Torre, de la, S., Pujol, M. A. y Rajadell, N. (coords.) (2005), El cine, un entorno educativo, Narcea, Madrid.

Touraine, A. (2000), ¿Podremos vivir juntos? Iguales y diferentes, Fondo de Cultura Económica, Buenos Aires.

Touriñán, J. M. (direc.) (2008), Educación en valores, educación intercultural y formación para la convivencia pacífica, Netbiblo, La Coruña.

Vallejos, A., Ortí, M. y Agudo, Y. (2007), Métodos y Técnicas de Investigación Social, Editorial Universitaria Ramón Areces, Madrid.

Zabalza, M. A. (2003), Competencias docentes del profesorado universitario. Calidad y desarrollo profesional, Narcea, Madrid.

\section{Medios electrónicos}

http://fr.wikipedia.org/wiki/Babel_(film,_2006) (5-10-2009).

http://www.elmundo.es/encuentros/invitados/2006/12/2287/index.html (510-2009).

http://www.lacoctelera.com/tags/alejandro-gonzalez-inarritu (5-10-2009). 